A pesquisa, cujos resultados são apresentados neste trabalho, foi realizada nos meses de maio e junho de 2006. Nove entrevistas, com duração média de quarenta minutos, foram realizadas na comunidade de Nova Colina, periferia de Sobradinho, cidade integrante do Distrito Federal.

É importante para nós compreender como a mulher elabora mentalmente e vive emocionalmente seu trajeto migratório, tanto quanto a percepção que ela faz das mudanças que imprime a esse itinerário, decorrentes das dinâmicas externas e internas de adaptação e integração à nova sociedade. Relevantes também são as mudanças impressas no itinerário e as relações decorrentes da função simbólica e psicofísica da maternidade nesse processo.

Para a mulher, autônoma ou acompanhada de companheiro ou de marido, a maternidade é um acontecimento que, em geral, ocorre cercado pela rede de relacionamentos familiar e comunitária, que apóia e auxilia tanto a mãe quanto o bebê. Embora um nascimento seja um evento naturalmente associado à mulher e sua ocorrên-

\footnotetext{
* Trabalho apresentado no Fórum Social Mundial das Migrações, de 22 a 25 de junho de 2006, em Rivas Vaciamadrid, Espanha, no Taller Migrante em cuerpo de mujer, dia 24 , às $15 \mathrm{~h}$.

** Pesquisadora do Centro Scalabriniano de Estudos Migratórios - CSEM. Atualmente é mestranda em lingüística pela Universidade de Brasília/ DF.

*** Religiosa missionária scalabriniana, socióloga, secretária e pesquisadora do Centro Scalabriniano de Estudos Migratórios - CSEM, de Brasília/DF.
} 


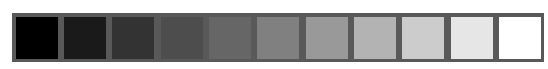

Tossin, L. F. \& Santín, L. T. Projeto migratório feminino

cia considerada um acontecimento corriqueiro na comunidade, é possível que essa normalidade seja compreendida de outras formas pela mulher migrante, para a qual um parto no contexto de relações familiares do lugar de origem pode ser diverso que em migração, onde ele pode se tornar um evento até mesmo traumatizante e desencadeador de processos inesperados.

O nascimento de uma criança sempre é um evento que provoca mudanças na rotina da mãe e/ou da família que o recebe; assim, a maternidade será o foco deste estudo para compreender que tipo de alteração um nascimento pode desencadear na expectativa - razões para permanecer, razões para se mudar novamente ou para voltar ao seu lugar de origem - que as mulheres migrantes possam elaborar em seu percurso migratório até Brasília. Combinam-se a esse foco outras questões complementares que ajudarão no estudo e poderão ser aprofundadas em outras ocasiões. Portanto, além do nascimento, integram-se os demais eventos da vida de uma pessoa, como constituição ou anulação de matrimônio, morte de familiar querido ou doença grave, por exemplo.

Buscamos, então, identificar a importância das redes de relacionamento na integração da mulher na sociedade de acolhida assim:

1. Relacionar o papel das redes de relacionamento no advento da maternidade;

2. Perceber quais as mudanças provocadas pela maternidade no trajeto migratório estabelecido antes do nascimento/ gestação;

3. Distinguir elementos que justifiquem a permanência ou a mudança;

4. Propor uma análise aprofundada que resulte em políticas públicas voltadas para o atendimento da mulher migrante.

Cabe ressaltar que existem múltiplos estudos nessa região central do Brasil, voltados para a questão migratória. Mesmo não tendo feito uma exaustiva revisão bibliográfica, temos a informação de trabalhos e pesquisas significativos voltados para a construção de Brasília e dentro dela a mobilidade humana. Porém, o tema específico 
sobre o projeto migratório feminino, com o enfoque no perfil de migrante por nós recortado, é novidade.

\section{Contextualização breve}

Durante as primeiras décadas de existência da nova capital do Brasil, o índice de crescimento populacional no Distrito Federal era um dos mais altos do país. Em um período de 10 anos, da década de 1960 até 1970, a população passou de 140 mil para aproximadamente 537 mil habitantes, tendo um crescimento médio anual de 14,4\% (QUEIROZ, 2006). Esse índice diminuiu na década de 1980, caindo para um patamar de aproximadamente 2,84\% (QUEIROZ, 2006) respectivamente. O processo migratório ocorrido durante essas três décadas, no DF, não cessou nas décadas posteriores.

Nessas três décadas, com a necessidade de espaço geográfico de moradia para esse contingente populacional, surgiram, em primeiro lugar, a chamada Cidade Livre, hoje, a atual Região Administrativa do Núcleo Bandeirante. Todavia, o fluxo intenso de migrantes que chegava à Capital era direcionado para assentamentos mais distantes do Plano Piloto, que propiciaram o surgimento de Taguatinga, Gama, Guará, Sobradinho, Ceilândia e, mais tarde, Samambaia, Recanto das Emas, Santa Maria, Riacho Fundo, entre outras cidades que atualmente formam o Distrito Federal com Brasília.

A mobilidade humana continua sendo intensiva, porém, nas regiões circunvizinhas ao Distrito Federal, o chamado Entorno, que serve de moradia e, algumas vezes, de posto intermediário no trajeto migratório até o DF. A maioria dos habitantes do Entorno possui algum tipo de ligação com o Distrito Federal, ao buscar trabalho, serviços de saúde e educação, assim, exercem pressão nos serviços assistenciais, no transporte e no mercado de trabalho que não tem tamanha capacidade de absorção de mão-de-obra desqualificada. Sobressai a migração de mulheres que vêm para Entorno e Distrito Federal para trabalharem como empregadas domésticas nos bairros de classe média de Brasília e demais Cidades. 
Porém, é importante considerar que, embora decrescente, a chegada de migrantes não significa redução na atração migratória do Distrito Federal, mas sim redirecionamento do fluxo para a região adjacente ao Distrito Federal, ou seja, o Entorno. A tabela abaixo é ilustrativa.

Tabela 1

População urbana, rural e taxa de crescimento entre 1991 e 2000 Municípios da RIDE

\begin{tabular}{|l|r|r|r|r|}
\hline \multirow{2}{*}{ Municípios } & \multicolumn{2}{|c|}{ População residente } & Total \\
\cline { 2 - 5 } & & Urbana & Rural & $\begin{array}{r}\text { Taxa de } \\
\text { crescimento }\end{array}$ \\
\hline Abadiania & 11.452 & 7.206 & 4.246 & 2,24 \\
\hline Água Fria de Goiás & 4.469 & 1.603 & 2.866 & 1,32 \\
\hline Águas Lindas de Goiás & 105.746 & 105.583 & 163 & 46,71 \\
\hline Alexania & 20.047 & 15.935 & 4.112 & 2,23 \\
\hline Buritis & 20.396 & 13.868 & 6.528 & 1,15 \\
\hline Cabeceira Grande & 5.920 & 4.579 & 1.341 & 1,18 \\
\hline Cabeceiras & 6.758 & 4.904 & 1.854 & 0,50 \\
\hline Cidade Ocidental & 40.377 & 34.465 & 5.912 & 3,82 \\
\hline Cocalzinho de Goiás & 14.626 & 6.000 & 8.626 & 3,83 \\
\hline Corumba de Goiás & 9.679 & 5.597 & 4.082 & 0,57 \\
\hline Cristalina & 34.116 & 27.569 & 6.547 & 3,58 \\
\hline Distrito Federal & 2.051 .146 & 1.961 .499 & 89.647 & 2,80 \\
\hline Formosa & 78.651 & 69.285 & 9.366 & 3,06 \\
\hline Luziania & 141.082 & 130.165 & 10.917 & 6,74 \\
\hline Mimoso de Goiás & 2.801 & 1.186 & 1.615 & $(3,22)$ \\
\hline Novo Gama & 74.380 & 73.026 & 1.354 & 4,92 \\
\hline Padre Bernardo & 21.514 & 13.272 & 8.242 & 3,02 \\
\hline Pirenópolis & 21.245 & 12.475 & 8.770 & 0,09 \\
\hline Planaltina & 73.718 & 70.127 & 3.591 & 7,03 \\
\hline Santo Antonio do Descoberto & 51.897 & 48.398 & 3.499 & 5,55 \\
\hline Unai & 70.033 & 55.549 & 14.484 & 1,50 \\
\hline Valparaíso de Goiás & 94.856 & 94.856 & & 7,09 \\
\hline Vila Boa & 3.287 & 2.702 & 585 & 1,50 \\
\hline Total & 2.888 .163 & 2.704 .300 & 183.863 & \\
\hline & & & & \\
\hline
\end{tabular}

Fonte:Censo demográfico 1991: resultados do universo: microdados. Rio de Janeiro: IBGE, 2002 7 CD-ROM: IBGE, Censo Demográfico 2000. Taxa de crescimento $=\left(((\text { Pop2000 } / \text { Pop1991) }(1 / n))-1)^{*} 100\right.$ 
No final da década de 1950 e início da década de 1960, algumas localidades do Entorno já ofertavam lotes para residências (QUEIROZ, 2006). Porém, a ocupação intensiva dessa área teve seu início no final da década de 1970. A razão econômica, altos preços para aquisição de terreno, foi a principal, entre outras, para a ocupação dessa área. O baixo poder aquisitivo, entre outras dificuldades, somado às necessidades, fez com que muitas áreas fossem ocupadas de forma irregular por milhares de migrantes pelo processo de grilagem e a conseqüente criação de novas localidades e condomínios. A escassez de moradia aliada à impossibilidade de adquirir solo e construir casas de uma significativa população continuou impulsionando ações de ocupação de espaços geográficos que permitiam habitar e a partir daí buscar meios de sobrevivência ou de vida melhor. A mobilidade humana do Entorno se deu tanto por migrantes que aqui chegaram no início da construção de Brasília como por aqueles que ainda chegam de outros Estados.

Nem todos os pioneiros que aqui chegaram, mesmo trabalhando duro de sol a sol, conseguiram um pedaço de chão para construir sua moradia e revelam seus anseios, também, em forma de poesia. Aliás, a bagagem cultural, expressa de tantas formas, entre elas o Cordel, traz consigo uma riqueza inigualável nas comunidades dos migrantes. Cito aqui apenas duas estrofes de um cordel ${ }^{2}$, que explicita uma das problemáticas vividas.

$$
\begin{aligned}
& \text { Bandeirante fez campanha } \\
& \text { Pras vilas não mudar } \\
& \text { Porém, rádios e jornais } \\
& \text { Ouviram-se anunciar } \\
& \text { Em uma cidade elegante } \\
& \text { la tudo se transformar. (04) } \\
& \text { No fim de cada mudança } \\
& \text { Ouvia-se comícios lindos } \\
& \text { Em uma placa tinha escrito } \\
& \text { Meu povo seja bem-vindo } \\
& \text { Bandeirante ficou triste } \\
& \text { Ceilândia ficou sorrindo. (05) }
\end{aligned}
$$

2 Cordel no DF: da Vila Amauri até a Casa do Cantador (Dissertação de Mestrado de Cléria Botelho da Costa). Departamento de História, Universidade de Brasília, p. 66. 
De acordo com os dados do IBGE, a população feminina do Distrito Federal, vinda de outros estados, alcança $28,8 \%$ do total da população no ano 2000. Portanto, mesmo com a forte diminuição da migração para o Distrito Federal há três décadas, as mulheres migrantes formam um terço da população, conforme dados do IBGE, 2000.

Total de mulheres não naturais do DF, total de nascidos vivos e população total - DISTRITO FEDERAL, 2000

\begin{tabular}{|l|c|c|}
\cline { 2 - 3 } \multicolumn{1}{c|}{} & Total & \% da população \\
\hline Mulheres não naturais & 592.497 & 28,8 \\
\hline Nascidos vivos & 47.991 & 2,34 \\
\hline População & 2.051 .146 & 100 \\
\hline
\end{tabular}

Fontes: IBGE - Censo Demográfico 2000, MS/SVS/DASIS -

Sistema de Informações sobre Nascidos Vivos - SINASC

Total de mulheres migrantes e de nascidos vivos em relação a população residente - DISTRITO FEDERAL, 2000

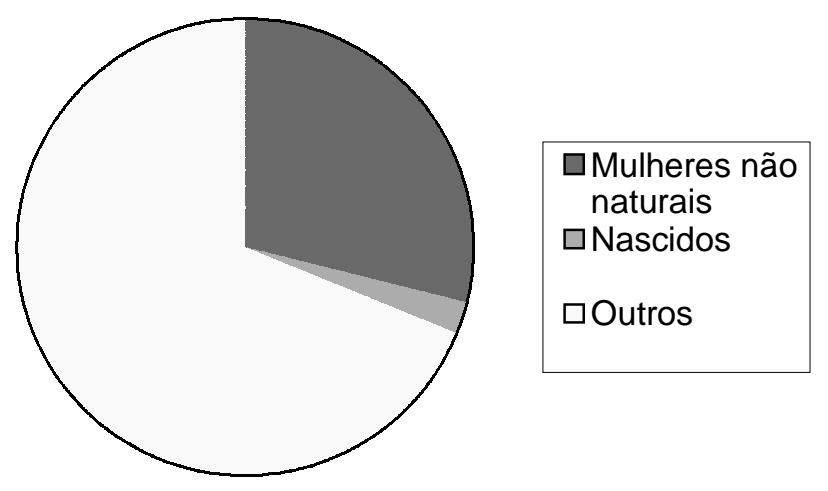




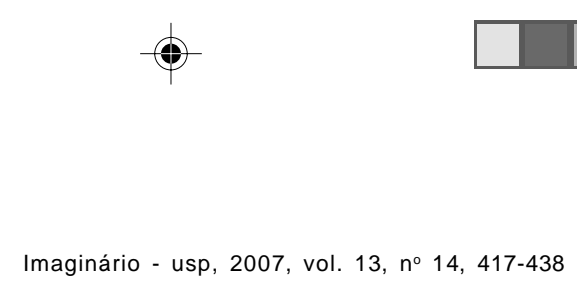

Nova Colina

Nova Colina surgiu há, aproximadamente, cinco anos como conseqüência da pressão imobiliária sobre a cidade de Sobradinho, formada, tipicamente, por famílias de classe baixa; hoje, entretanto, considerada expansão da classe média do Plano Piloto de Brasília. A impossibilidade de pagar valores mais altos nos aluguéis e nos impostos provocou várias famílias a abandonarem Sobradinho, dirigindo-se mais para Norte e ocupando, dois quilômetros adiante, um trecho anteriormente destinado à produção agrícola.

O parcelamento das chácaras deu origem a um conglomerado de condomínios irregulares, mal distribuídos espacialmente, o que criou ruas tortuosas, endereços repetidos, numeração descontínua e confusa. A maioria dos moradores, quando interrogados sobre a localização de determinado endereço, não sabia orientar. Por ser irregular, os moradores não possuem escritura dos imóveis, não recebem infra-estrutura, como rede de esgoto e água, linhas de ônibus, telefonia e asfalto. Onde imperam necessidades, o alternativo cobre as deficiências do serviço público e a comunidade é atendida por uma numerosa frota de microônibus, as lotações.

Tendo em vista o caráter precário das instalações e a recente ocupação, Nova Colina é compreendida como local de migração recente. Entendemos por migração, no contexto urbano, aqueles deslocamentos intra-urbanos, entre cidades dentro da mesma área metropolitana, ou seja, famílias que precisaram deslocar-se a fim de fugir da especulação imobiliária. Dessa forma, a maioria dos moradores é formada por pessoas que nasceram ou residem no Distrito Federal ou Entorno há muito tempo, embora Nova Colina tenha apenas cinco anos de existência.

A migração, seja ela para uma zona distante seja para uma relativamente próxima, como é o caso de Nova Colina, causa expectativas e provoca frustrações que se tornam visíveis no depoimento de uma informante, trabalhadora e filha da dona do salão Realce, um dos tantos empreendimentos dedicados à beleza feminina na co- 


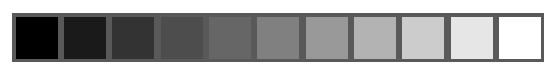

Tossin, L. F. \& Santín, L. T. Projeto migratório feminino

munidade (que nos indicam a preferência estética dessa classe social: o cuidado com os cabelos, alisamentos e escovas, e as unhas), quando, indignada com o perfil feminino alcançado pela pesquisa, comentou: "Por que só com as recém-chegadas? Eu estou aqui há 27 anos e não estou estabilizada coisa nenhuma!".

A falta de condições econômicas adequadas para suprir suas necessidades impulsiona essas famílias a se mudarem com freqüência de uma casa para outra, em busca de aluguéis mais baratos, o que possibilitaria, em tese, o cumprimento do contrato, porém, a estratégia parece não funcionar e a mudança para localidades cada vez mais distantes do posto em que essas pessoas trabalham causa, além de acúmulo no gasto com transporte, efeitos negativos no ambiente familiar que podem levar à desorganização familiar e emocional do indivíduo que sofre contínuas mudanças de endereço.

\section{Metodologia}

As entrevistas foram realizadas, à exceção de uma, nos locais de moradia. A pessoa interrogada era, na maior parte das vezes, esposa do chefe de família. Foram nove mulheres, com idades de 18 a 33 anos, migrantes internas residentes no Distrito Federal há mais de seis meses e menos de cinco anos e que tiveram bebê neste período crítico de adaptação. Estabeleceu-se uma pré-seleção junto às agentes de saúde responsáveis pela comunidade, sendo que uma delas acompanhou as visitas no primeiro e segundo dias.

O esquema de entrevista usado nesta pesquisa compreendia a história da gestação dos filhos nascidos em Brasília, as impressões a respeito do atendimento tanto no posto de saúde quanto no hospital, o envolvimento familiar, a história da família, de sua migração, as expectativas criadas na e pela migração e a profissão, distribuídas em grupos por assunto, bem como as relações que marcam o processo e o momento atual na "terra de acolhida". 
Essas entrevistas foram objeto de análise de conteúdo, utilizandose uma ficha organizada de forma que todas as respostas dadas para uma pergunta ficassem juntas, facilitando assim o acesso à informação desejada e possibilitando a comparação dos diferentes depoimentos.

\section{Maternidade como expressão corporal}

A maternidade é, antes de tudo, um evento diretamente manifestado no corpo. Porém, interessa-nos aqui não os aspectos meramente funcionalistas do corpo que dizem respeito às disciplinas mais privilegiadas de estudo e pesquisa nesta área e que percebem o corpo como uma ferramenta com necessidades especiais de funcionamento que devem ser atendidas para que esse corpo possa executar as atividades sociais que lhe são determinadas.

Desnaturalizar a maternidade é possibilitar a perspectiva de que, mesmo a reprodução, entra no "sistema das relações entre as diferentes dimensões do comportamento corporal (que) implica na ruptura com a situação prática definida por uma necessidade social" Como coloca Bourdieu:

Ora, não é senão com a condição de romper com a relação 'prática' implicada em toda situação em que o corpo do outro é objeto de uma estratégia, quer seja ela terapêutica ou ética, colocando-se como observador num ponto em que o corpo pode aparecer sob a pluralidade de seus aspectos, que se poderá operar a construção, primeiramente do sistema de relações entre o conjunto dos comportamentos corporais dos membros de um mesmo grupo e, em segundo lugar, do sistema das relações que unem esses comportamentos e as condições objetivas de existência próprias a esse grupo, relações estas que só podem ser estabelecidas, como se verá mais adiante, se se proceder à análise e à descrição da cultura somática característica desse grupo (BOURDIEU, 2004, p. 106). 


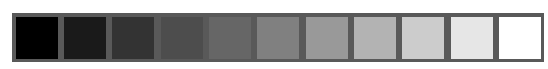

Tossin, L. F. \& Santín, L. T. Projeto migratório feminino

Para Bourdieu (2004), a cultura somática de cada grupo determina seus comportamentos corporais e ele faz a distinção entre os procedimentos das classes populares e das mais abastadas tendo como parâmetros a capacidade de consumo de cada grupo e a força física empregada no trabalho, mais usada entre as classes populares de forma mais intensa e mais freqüente no ambiente de trabalho. A força e a resistência são, então, valores cultivados para as classes populares.

Assim, a anemia gestacional comumente presente em mulheres de todas as classes sociais poderia provocar, nas classes populares, a compreensão de que a gravidez fosse também uma doença, visto que a anemia provoca a "fraqueza", que impossibilita o trabalho. Isso associado ao contato freqüente com médicos e práticas sanitárias específicas levaria a gravidez ao status de distúrbio físico, um momento limítrofe entre saúde e doença, já que a fertilidade é uma característica tida como positiva tanto para mulheres quanto para homens. Daí o caráter "especial" da mulher grávida, como me esclareceu uma informante a respeito das gestações no princípio do século passado em sua família.

Ah! As mulheres usavam aqueles vestidos escuros, bem largos, era azul-marinho, preto ou marrom, pelo menos no interior onde a gente morava era assim. Acho que era uma forma de esconder das outras crianças, para que ninguém perguntasse de onde vinham os bebês. De repente, aparecia um bebê na família. Elas diziam assim: "Chegou a hora. A fulana adoeceu de madrugada".

A menção ao "adoecimento" da gestante no momento de início do trabalho de parto, assim como aos "vestidos escuros", nos remetem a atmosfera e expectativa sombrias, momento no qual tanto a morte quanto o nascimento poderiam acontecer. O luto na gestação está implícito no uso das cores preta, azul-marinho e marrom. O silêncio a respeito da gravidez tanto pode evocar o puritanismo exagerado que não distingue discursivamente a educação sexual da obscenidade, principalmente, no ambiente familiar e com relação às crianças (BOURDIEU, 2004, p. 137), quanto o temor da morte materno-infantil no parto. 
Para as mulheres entrevistadas, a gravidez foi a primeira ou a única vez em que foram ao hospital ou posto de saúde para receber atendimento. Algumas justificaram alegando o fato de que, na roça, utilizam-se mais plantas e remédios caseiros, por isso procuram menos os serviços de saúde. Porém, após o parto, só buscam esses serviços para atendimento pediátrico, sinalizando que a situação "especial" de gravidez já passou, portanto, não é mais necessário acompanhamento médico.

A idéia de que a gravidez está na zona limítrofe entre doença e saúde nos provoca a pensar em por que essas mulheres que vieram, em sua maioria, morar sozinhas no Distrito Federal rapidamente encontraram parceria sexual e engravidaram.

A tendência de migrar e engravidar logo após a mudança se repete na vida de algumas mulheres que possuem quase tantos filhos quantas foram as vezes que migraram de uma cidade para outra, muitas vezes de diferentes pais.

\begin{tabular}{|c|c|}
\hline $\begin{array}{l}\text { Número de vezes } \\
\text { que migrou }\end{array}$ & Número de filhos \\
\hline 1 & Está gestando o primeiro. \\
\hline 1 & Uma filha, mora com a avó. Está gestando o segundo. \\
\hline 1 & Está gestando o primeiro. \\
\hline 6 & $\begin{array}{l}4 \text { gestações - } 2 \text { filhos e } 2 \text { filhas, sendo que a filha } \\
\text { mais velha está com a avó. }\end{array}$ \\
\hline 5 & $\begin{array}{l}4 \text { gestações - } 2 \text { filhos e } 2 \text { filhas, sendo que o filho } \\
\text { mais velho está com a tia. }\end{array}$ \\
\hline 1 & $\begin{array}{l}2 \text { gestações. } 1 \text { filha que está com a avó e um } \\
\text { aborto que ocorreu há pouco tempo. }\end{array}$ \\
\hline 6 & 6 gestações - 4 filhos e 0 filhas, todos com ela. \\
\hline 2 & 2 gestações - 1 filho e 1 filha, ambos com ela. \\
\hline 2 & $\begin{array}{l}3 \text { gestações - } 2 \text { filhos e } 1 \text { filha. O marido tem uma } \\
\text { filha com outra mulher. A menina está com a avó. }\end{array}$ \\
\hline
\end{tabular}

Fonte: respostas dadas às perguntas - tempo de moradia em Brasília; número de vezes que migrou; número de filhos; com quem moram. 


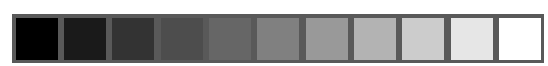

Tossin, L. F. \& Santín, L. T. Projeto migratório feminino

Uma informante esclareceu desta forma:

Depois que eu me separei, saí de Santa Maria' e fui para Luziânia, onde moram minhas duas irmãs e meus dois irmãos. Minha família não aceitava minha separação, então, eu pensei em casar novamente para reorganizar minha vida e reatar os laços com a minha família. Não deu certo, acabei ficando com o R. (filho gerado neste relacionamento). Aí eu comecei a namorar um rapaz que trabalhava comigo. Foram três meses de relacionamento, ele queria casar, mas eu não queria, já tinha entendido que eu não iria reorganizar minha vida casando de novo, mas aí eu engravidei. Fiquei com muita raiva, não aceitava aquilo, eu queria tirar. Foi nessa época que uma Irmã da Pastoral foi lá em casa fazer trabalho de base comigo e eu aceitei o convite para passar o final de semana no acampamento do Movimento dos Trabalhadores Desempregados, fiquei um mês, gostei e acabei entrando para o movimento. J. nasceu no acampamento do Pipiripau. Eu me apaixonei lá também, mas cada homem que eu tenho eu arranjo um filho, então, eu resolvi não falar nada para ele e deixar por isso mesmo.

Na compreensão do filósofo e teólogo Dussel, a relação afetiva entre homens e mulheres é o reconhecimento máximo da alteridade, a ponto de amar alguém externo à própria percepção existencial de si. Assim, se transforma em alteridade máxima com o surgimento do fruto dessa relação, ou seja, o filho, pois o filho é, em sua essência, tanto "eu" quanto "outro".

el outro de la fecundidad: el hijo; la causa procreante Del hijo es um amor de pura bondad, es la liberdad fecunda de uma pareja, bendice la relación durable haciéndola eterna em su propia contituición real (DUSSEL, 1988, p.106) ${ }^{2}$. Então, o filho nascido deste amor não será o filho do eterno retorno, e sim, o 'outro' de um tempo novo, de um ato libertador, de uma nova história, (...) (GROLLI, 2004, p. 79).

Se entendermos que o filho é a expressão máxima da capacidade de amar o outro, então, para essas mulheres, o amor está corporificado na gravidez, manifestado como expressão corporal da tangibilidade do sentir. 
A repetição da seqüência: migrar, apaixonar-se e ter filhos acarreta em um volume crescente de rupturas, desorganizações estruturais e filhos sob a responsabilidade da mulher, o que integra no seu corpo traços de sofrimentos marcados, marcas de um passado latente que se torna presente visivelmente. Um corpo que incorpora o novo com sentimento e bagagem já adquirida. Um corpo que se esfacela e ao mesmo tempo se rejunta tendo como centro essas forças opostas à criança.

Uma entrevistada, ao falar sobre filhos declara, emocionada, entre lágrimas:

Eu deixei um filho, eu não dei, eu deixei porque não tinha condições de trazer comigo. Cheguei aqui e logo arrumei outro, isso me dói. Não deixei porque quis, nem tenho esse [com a criança no colo] porque quis. Me dói, me dói porque acho que se um dia eu for buscar o meu mais velho (tem 8 anos) ele não vai querer vir comigo. O mais velho e o mais novo e também esses do meio (que estavam perto de seus pés no chão), eu amo todos igual.

O filho que chegou e o filho que ficou. Ambos estão enredados na decisão materna de migrar. A dificuldade de criar o primeiro filho impulsionou essa mãe a migrar para Brasília com a intenção de adquirir condições de manter a si, aqui, e ao filho que ficou lá. Porém, a chegada dos filhos sucedentes, apesar de garantirem a ela a estadia em Brasília, pois com tantos filhos já não era possível voltar, impede-a de realizar plenamente seu anseio inicial da migração.

Porém, essa lógica de relacionamento afetivo possui uma economia que se adapta à necessidade dessas mulheres, que buscam, por meio dos relacionamentos afetivos e dos filhos gerados nesses relacionamentos, ascender a redes de relacionamento familiar e social anteriormente inexistentes, como relata uma informante quando perguntada sobre a chegada dos bebês em casa:

Eu engravidei logo que cheguei aqui. Liguei pra minha mãe, mesmo que ela não quisesse que eu me casasse com esse meu marido. Fui ter o meu filho na casa dela, ela que me acompanhou 


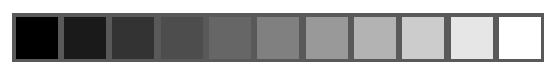

Tossin, L. F. \& Santín, L. T. Projeto migratório feminino

no hospital e me cuidou por 10 dias, depois eu voltei para casa [a mãe mora no local de origem da entrevistada]. Essa aqui [referindo-se à menina de 7 meses que tinha no colo] eu tive aqui, minha sogra me ajudou, as irmãs da Igreja me ajudaram muito, a mulher do pastor me deu um montão de fraldas.

Expor-se ao risco de viver o limite entre saúde e doença em um ambiente novo, no qual, muitas vezes, são escassos os recursos materiais, traz, embutida no risco, a oportunidade de estabelecer relações familiares com os parentes do marido das quais decorre muitas vezes a possibilidade de ter uma casa nos fundos da propriedade da sogra ou da cunhada. A casa própria é o bem mais almejado pelas mulheres que chegam, como podemos perceber na fala de uma informante: "Meu sonho é ter um cantinho pra poder deixar de mudar todo mês".

Assim como ser incluída em programas específicos de saúde, com acompanhamento de agentes de saúde específicos para esse fim, rompendo com sua situação deslocada em relação ao ambiente em que recém-chegou. Dessa forma, a mulher se estabelece física e socialmente naquela comunidade, por meio do filho que nasce, e por esse evento a trama de relações acontece.

Trabalho e gravidez

As mulheres, como mencionado anteriormente, são protagonistas e maioria no caminho da migração no Distrito Federal. Em grande parte, vêm para Brasília com o intuito de trabalharem como domésticas (IBGE, 2000). O trabalho doméstico é um dos meios de inserção da mulher no mercado de trabalho visto que a casa é o espaço privado, comumente associado ao feminino, às tarefas femininas, como o trabalho doméstico. Nesse espaço, supõe-se a proteção contra as agressões e violências oriundas do mundo exterior, ou seja, do espaço público, a rua. 
Nela evoca-se a competitividade, a agressividade e a assertividade, características tidas como inadequadas para a mulher. Dessa forma, reprimem-se tais atitudes para o feminino quando se restringe seu papel ao ambiente doméstico em que o trabalho servil (de servir ao outro) se faz maior.

A repressão se repete ao longo de gerações sucessivas, acumulando a desvalorização da curiosidade e da inteligência feminina, desmo-tivando sua inserção no mercado e oprimindo seu desenvolvimento intelectual (ZUWICK, 2001). Percebemos que esse mecanismo se repete na fala de uma informante:

Meu marido é servente de pedreiro e ganha $R \$ 90,00$ por semana. Sai cedo de casa, leva a marmita que eu preparo pra ele. Agora que eu me casei, não preciso mais trabalhar.

Em algum momento, a experiência e os efeitos da migração levam a mulher a refletir sua condição e elaborar convicções expressandoas para que tal situação não seja repetida com as suas irmãs que ainda estão na origem.

Tive neném cedo demais por não ter tido instrução nenhuma. Agora ligo para minha mãe e digo para ela cuidar das minhas duas irmãs mais novas, digo "dê instrução e ocupação e estudo". Se as condições fossem outras seria diferente comigo.

Embora a perspectiva tenha mudado durante a experiência migratória de algumas mulheres, ainda buscam no amor, ou no fruto do amor, sua inserção e sua afirmação social perante a sociedade de acolhida.

A sexualidade, então, pode ser usada como forma de apropriação do espaço novo pela mulher migrante de forma distinta da prostituição que tem fins comerciais e, invariavelmente, está dissociada da construção de relacionamentos afetivos e familiares. Pretendemos trazer esse novo ponto para entendermos como as mulheres migrantes constroem suas referências identitárias na sociedade de acolhida. 
A mulher elabora mentalmente e vive emocionalmente seu trajeto migratório ao reconstruir as imagens de sua vida. Nessa reconstrução, transparece o sentimento que simbolicamente traz à tona a saudade ou a dor de um projeto deixado para trás; atitudes muitas vezes negadas, mas que na reelaboração do projeto migratório igualam-se à possível realidade.

A motivação, apoiada pelos laços parentais e fraternos na busca por melhores condições de vida, de trabalho e de possibilidade de estudo são a origem do querer partir das migrantes contempladas nesse universo da pesquisa.

Não restam dúvidas de que o percurso migratório dessas mulheres foi impulsionado prioritariamente pelas precárias condições de ascensão social e vida digna no local de origem. Entendendo assim, surge a questão "sonhos, imagens, fantasias" na experiência de vida dessas mulheres. Suas partilhas de vida, durante a entrevista, se observadas por esse ângulo, permitem a compreensão da resistência e da luta perseverante dessas mulheres, por continuarem buscando respostas a suas metas, seus sonhos.

\begin{tabular}{|l|l|l|}
\hline Motivos da migração & Situação atual & Sonhos \\
\hline Casamento. & $\begin{array}{l}\text { Tem um filho e não } \\
\text { casou no religioso. }\end{array}$ & Realizar casamento. \\
\hline $\begin{array}{l}\text { Situação familiar - } \\
\text { separação. }\end{array}$ & $\begin{array}{l}\text { Encontrou outro } \\
\text { companheiro em } \\
\text { menos de 5 meses, } \\
\text { está grávida. }\end{array}$ & Viver em paz. \\
\hline Estudo e trabalho. & $\begin{array}{l}\text { Nada disso } \\
\text { aconteceu. }\end{array}$ & $\begin{array}{l}\text { Sonho com um } \\
\text { cantinho meu, uma } \\
\text { casa. }\end{array}$ \\
\hline
\end{tabular}




\begin{tabular}{|l|l|l|}
\hline Ter uma vida melhor. & $\begin{array}{l}\text { Estou com as mãos } \\
\text { amarradas, o último } \\
\text { filho me impediu de } \\
\text { voltar a trabalhar. }\end{array}$ & De ser independente. \\
\hline $\begin{array}{l}\text { Suicídio do sogro. A } \\
\text { sogra ficou sem } \\
\text { recursos econômicos } \\
\text { e sem possibilidade de } \\
\text { permanecer no local, } \\
\text { aí mudaram-se todos. }\end{array}$ & $\begin{array}{l}\text { Sem marido, com 6 } \\
\text { filhos, residindo e } \\
\text { trabalhando como } \\
\text { monitora em uma casa } \\
\text { de menores. }\end{array}$ & $\begin{array}{l}\text { Ter seu pedaço de } \\
\text { terra, um lote de } \\
\text { ovelhas e montar um } \\
\text { trabalho alternativo } \\
\text { com mulheres da roça. }\end{array}$ \\
\hline Emprego, vida melhor. & $\begin{array}{l}\text { Trabalha de autônoma, } \\
\text { distribuição de } \\
\text { propagandas. }\end{array}$ & $\begin{array}{l}\text { Ter um trabalho melhor } \\
\text { e condições para dar } \\
\text { conta das } \\
\text { necessidades básicas } \\
\text { da família. }\end{array}$ \\
\hline
\end{tabular}

Respostas às questões gerais das entrevistas.

Entendendo por imaginário uma inter-relação de imagens e idéias, diferenciadas para cada indivíduo (PASSERINI, 1993, p. 32), surge, assim, a questão: o que focaliza a busca pelo novo nesse percurso? Parece-me que as respostas que motivaram a migração não esgotam seu significado no elenco dos elementos acima demonstrados. Desdobram-se na construção de outros afazeres cotidianos dos seres humanos e do simbólico, do entendimento analítico deles, da compreensão do imaginário e dos fazeres, da sua inter-relação com a teoria existente e, evidentemente, não aprofundada aqui.

O cuidado da família, possuir uma casa, assim como o reconhecimento da legalidade das uniões matrimoniais que vivem faz parte da ligação do imaginário com o real. A dinâmica cotidiana da vida orienta suas ações, ao mesmo tempo, que exige o pertencimento a instituições religiosas e sociais - redes simbólicas que contam com um componente funcional e um componente imaginário (CASTORIADIS, 1982, p. 52) e que também apontam normas para o comportamento 


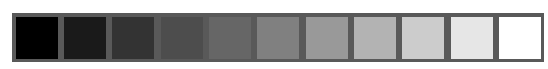

Tossin, L. F. \& Santín, L. T. Projeto migratório feminino

humano como forma de inserção na realidade da nova comunidade. Uma das informantes relatou sobre como estava apreensiva com o fato de não poder batizar o filho recém-nascido, pois não era casada no religioso e seu marido nem sequer a Primeira Comunhão havia feito. Seu maior desejo, então, nesse momento, passara a ser casar-se na Igreja, pois havia migrado para Brasília para casar-se com seu primeiro namorado, que viera um ano antes, já tinham um filho, mas o casamento não se realizara ainda. Para ela sua inserção social era precária e, agora, já afetava o filho, que não podia ser batizado.

A vida árdua da maioria das mulheres, universo desta pesquisa, perpassada por dificuldades de moradia fixa, condições econômicas precárias, tristezas, descontentamentos conjugais, incertezas e, ao mesmo tempo, muita coragem para enfrentar o cotidiano, deixar para trás suas memórias de mulheres do interior, da roça - motivação de suas trajetórias -, o imaginário fez com que elas recriem as esperanças continuamente, "de qualquer jeito tudo aqui é melhor".

Apesar de não existirem vantagens materialmente, percebe-se a existência delas no plano psíquico. Por dentro das respostas dessas mulheres se compreende que as mudanças trouxeram um veio de reelaboração do próprio projeto migratório, mesmo que ele possa ainda não estar totalmente integrado na vida das migrantes, mas aponta para a possibilidade do novo.

Não existem vantagens materialmente. Mas psicologicamente sim, as mudanças na minha vida me trazem sofrimentos, mas possibilitam que eu cresça e me desenvolva interiormente, pessoalmente. Eu tentei voltar para a roça, voltei, mas não encontrei meios para sustentar minhas duas filhas e meus quatro filhos. Não existe estrutura nem ambiente para mulher separada na roça.

Percebe-se aqui que paradoxalmente o imaginário passou a desempenhar um papel crescente na vida dessas mulheres na medida em que elas e tantas outras no mesmo espaço geográfico, umas há mais tempo, outras há menos tempo, todas oriundas do interior cidade pequena ou roça - continuam teimosamente buscando seu 
espaço social, econômico, religioso nas proximidades da cidade central.

Os filhos, os que ficaram para trás e os que no novo lugar nasceram, passam a ocupar, na vida real e no imaginário, uma centralidade, sustentando, assim, as ações, ainda que vivessem em profundo conflito entre a racionalidade do mundo concreto e o sonho da nova possibilidade.

Quando eu conseguir meu cantinho e um salário melhor - porque aqui sou pai e sou mãe, sou tudo, sabe como é -, então vou buscar meu filho mais velho (8 anos). Os filhos são minha razão e minha vida.

Resumo: A pesquisa, cujos resultados são apresentados neste trabalho, foi realizada nos meses de maio e junho de 2006. Nove entrevistas, com duração média de 40 minutos, foram realizadas na comunidade de Nova Colina, periferia de Sobradinho, cidade integrante do Distrito Federal. É importante para nós compreender como a mulher elabora mentalmente e vive emocionalmente seu trajeto migratório, tanto quanto a percepção que ela faz das mudanças que imprime a esse itinerário, decorrentes das dinâmicas externas e internas de adaptação e integração à nova sociedade. Relevantes também são as mudanças impressas no itinerário e as relações decorrentes da função simbólica e psicofísica da maternidade nesse processo. Segundo Bourdieu (2004), a cultura somática de cada grupo determina seus comportamentos, portanto, desnaturalizar a maternidade é possibilitar a perspectiva de que, mesmo a reprodução, entra no "sistema das relações entre as diferentes dimensões do comportamento corporal (que) implica na ruptura com a situação prática definida por uma necessidade social". A repetição da seqüência: migrar, apaixonar-se e ter filhos acarreta em um volume crescente de rupturas, desorganizações estruturais e filhos sob a responsabilidade da mulher, integrando em si as marcas dos sofrimentos vividos, como traços de um passado latente 


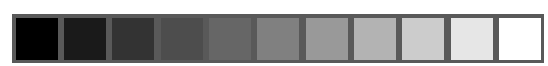

Tossin, L. F. \& Santín, L. T. Projeto migratório feminino

que se torna presente na expressão visível do seu ser: o corpo.

Palavras-chave: projeto migratório feminino, sexualidade, gravidez na migração.

\begin{abstract}
The research, whose results are presented in this work, was carried out through May and June of 2006. Nine interviews, with an average duration of 40 minutes, were carried out in the community of Nova Colina, periphery of Sobradinho, an integrant city of the Federal District. It is important for us to understand how women mentally elaborate and live emotionally her migratory route, as much as their perception of the changes they make in this route, arising from the external and internal dynamics of adaptation and integration to the new society. As relevant as that are the changes printed in their route and the relationships derived from the symbolic and psychophysical function of the maternity in this process. According to Bourdieu (2004), the somatic culture of each group determines their behaviors and, therefore, denaturalizing maternity is to make possible the perspective that, even the reproduction enters in the "system of relations between the different dimensions of the corporal behavior (that) implies in the breakage with the practical situation defined by a social necessity". The repetition of the sequence: to migrate, fall in love and have children causes an increasing volume of breakages, structural disorganizations and children under the woman's responsibility, integrating in her body the marks of the sufferings experienced, as well as traces of a latent past that becomes present in the visible expression of her self: the body.
\end{abstract}

Key words: women's migratory project, sexuality, pregnancy in migration. 


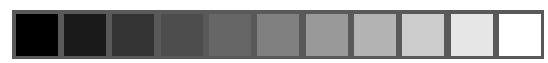

Imaginário - usp, 2007, vol. 13, n 14, 417-438

Resumen: La investigación, cuyos resultados son presentados en este trabajo, fue realizada en los meses de mayo y junio de 2006. Nueve entrevistas, con duración aproximada de 40 minutos, fueron realizadas en la comunidad de Nova Colina, periferia de Sobradinho, ciudad integrante del Distrito Federal $^{2}$. Es importante comprender como la mujer elabora mentalmente y vive emocionalmente su trayecto migratorio, así como, la percepción que hace de los cambios que imprime a ese itinerario, consecuencia de las dinámicas externas e internas de adaptación e integración a la nueva sociedad. También son relevantes los cambios en el itinerario y las relaciones producto de la función simbólica y psicofísica de la maternidad en ese proceso. Según Bourdieu (2004), la cultura somática de cada grupo determina sus comportamientos, por lo tanto, desnaturalizar la maternidad es posibilitar la perspectiva de que, inclusive la reproducción, entra en el "sistema de las relaciones entre las diferentes dimensiones del comportamiento corporal (que) implica en ruptura con la situación práctica definida por una necesidad social”. La repetición de la secuencia: migrar, enamorarse y tener hijos implica en un volumen creciente de rupturas, desorganizaciones estructurales e hijos bajo la responsabilidad de la mujer, integrando en si las marcas de los sufrimientos vividos, como trazos de un pasado latente que se torna presente en la expresión visible de su ser: el cuerpo.

Palabras clave: proyecto migratorio femenino, sexualidad, embarazo en la migración. 


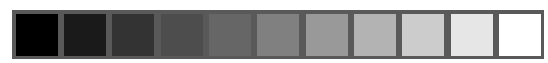

Tossin, L. F. \& Santín, L. T. Projeto migratório feminino

\section{Bibliografia}

BOURDIEU, P. A dimensão social dos comportamentos do corpo. In: BOLTANSKI, L. As classes sociais e o corpo. São Paulo: Paz e Terra, 2004. p. 106 (A adequação sintática foi feita pela autora).

. A cultura somática. In: BOLTANSKI, L. As classes sociais e o corpo. São Paulo: Paz e Terra, 2004. p.137.

CASTORIADIS, C. A Instituição Imaginária da Sociedade. Rio de Janeiro: Paz e Terra, 1982. p. 52.

Costa, C. B. da . Cordel no DF: da Vila Amauri até a Casa do Cantador. (Dissertação de Mestrado). Departamento de História, Universidade de Brasília, p. 66.

DUSSEL, E. Filosofia ética de la liberación. V. III Erótica e pedagógica. Buenos Aires: Ediciones Megápolis, 1988.

GROLLI, D. Alteridade e Feminino. São Leopoldo: Nova Harmonia, 2004, p. 79.

QUEIROZ, E. P. de. A migração intrametropolitana no Distrito Federal e Entorno: o conseqüente fluxo pendular e o uso dos equipamentos urbanos de saúde e educação. XV Encontro Nacional de Estudos Populacionais, ABEP, realizado em Caxambu, MG, de 18 a 22 de setembro de 2006. <disponível em: http://www.abep.nepo. unicamp.br/encontro2006/docspdf/ABEP2006_724.pdf >

ZUWICK, A. M. Emancipação feminina: obstáculos para sua construção. In: Construções e Perspectivas em Gênero. São Leopoldo: Unisinos, 2001.

PASSERINI, L. Mitobiografia em História Oral. In: Revista Projeto História. n. 10, dez. 1993, p. 32. 